\title{
Cortical Metabolic Activity Matches the Pattern of Visual Suppression in Strabismus
}

\author{
Daniel L. Adams, ${ }^{1,2}$ John R. Economides, ${ }^{1}$ Lawrence C. Sincich, ${ }^{3}$ and Jonathan C. Horton ${ }^{1}$ \\ ${ }^{1}$ Beckman Vision Center, University of California, San Francisco, San Francisco, California 94143, ${ }^{2}$ Center for Mind/Brain Sciences, The University of \\ Trento, I-38122 Trento, Italy, and ${ }^{3}$ Department of Vision Sciences, University of Alabama at Birmingham, Birmingham, Alabama 35294
}

When an eye becomes deviated in early childhood, a person does not experience double vision, although the globes are aimed at different targets. The extra image is prevented from reaching perception in subjects with alternating exotropia by suppression of each eye's peripheral temporal retina. To test the impact of visual suppression on neuronal activity in primary (striate) visual cortex, the pattern of cytochrome oxidase ( $\mathrm{CO}$ ) staining was examined in four macaques raised with exotropia by disinserting the medial rectus muscles shortly following birth. No ocular dominance columns were visible in opercular cortex, where the central visual field is represented, indicating that signals coming from the central retina in each eye were perceived. However, the border strips at the edges of ocular dominance columns appeared pale, reflecting a loss of activity in binocular cells from disruption of fusion. In calcarine cortex, where the peripheral visual field is represented, there were alternating pale and dark bands resembling ocular dominance columns. To interpret the $\mathrm{CO}$ staining pattern, $\left[{ }^{3} \mathrm{H}\right]$ proline was injected into the right eye in two monkeys. In the right calcarine cortex, the pale CO columns matched the labeled proline columns of the right eye. In the left calcarine cortex, the pale $\mathrm{CO}$ columns overlapped the unlabeled columns of the left eye in the autoradiograph. Therefore, metabolic activity was reduced in the ipsilateral eye's ocular dominance columns which serve peripheral temporal retina, in a fashion consistent with the topographic organization of suppression scotomas in humans with exotropia.

\section{Introduction}

Many people with strabismus alternate fixation between the eyes. This ability is especially common in exotropia (Cotter et al., 2009). It has been controversial how diplopia is avoided in strabismus, given that the ocular axes point in different directions (Joose et al., 2000). In a recent study, the visual fields were mapped binocularly under dichoptic conditions in a cohort of subjects with alternating exotropia and normal visual acuity in each eye (Economides et al., 2012). Perception was not suppressed completely in the deviated eye. Instead, visual field maps showed a vertical border passing approximately midway between the center of gaze in each eye, dividing the binocular field into two separate zones (Fig. 1). In each zone, perception was governed by only one eye, while the other eye was suppressed. The zone of suppression corresponded to the peripheral temporal retina of each eye. Surprisingly, the fovea of the deviated eye was not suppressed. To avoid visual confusion, its perceived location was shifted to offset the ocular

Received July 6, 2012; revised Dec. 14, 2012; accepted Jan. 3, 2013.

Author contributions: D.L.A., J.R.E., L.C.S., and J.C.H. designed research; D.L.A., J.R.E., L.C.S., and J.C.H. performed research; D.L.A., J.R.E., L.C.S., and J.C.H. analyzed data; D.L.A., J.R.E., L.C.S., and J.C.H. wrote the paper.

This work was supported by Grants EY10217 (J.C.H.) and EY02162 (Beckman Vision Center) from the National Eye Institute, the Disney Award from Research to Prevent Blindness (J.C.H.), and a University of Alabama at Birmingham Impact Fund (L.C.S.). The California Regional Primate Research Center is supported by NIH Base Grant RR00169. Technical support was provided by Cristina M. Jocson and Valerie L. Wu.

Correspondence should be addressed to Dr. Jonathan C. Horton, Beckman Vision Center, University of California, San Francisco, 10 Koret Way, San Francisco, CA 94143-0730. E-mail: hortonj@vision.ucsf.edu.

DOI:10.1523/JNEUROSCI.3228-12.2013

Copyright $\odot 2013$ the authors $\quad 0270-6474 / 13 / 333752-08 \$ 15.00 / 0$ deviation, a phenomenon known as anomalous retinal correspondence (von Noorden and Campos, 2002).

The primary (striate) visual cortex contains alternating bands of inputs serving each eye, called ocular dominance columns (Hubel and Wiesel, 1977; LeVay et al., 1985). It also contains an orderly retinotopic map (Daniel and Whitteridge, 1961; Van Essen et al., 1984). If information from each eye's peripheral temporal retina is suppressed in alternating exotropia, one should expect a decrement in neuronal activity in the ipsilateral eye's ocular dominance columns in the representation of the peripheral visual field (Fig. 1). The relative level of neuronal activity in the cortex can be assessed by cytochrome oxidase (CO) histochemistry (Deyoe et al., 1995). In normal animals, there is a uniform distribution of CO staining in layer 4C (Horton, 1984). In contrast, after removal of one eye, ocular dominance columns become visible, owing to reduced activity in neurons driven formerly by the missing eye (Horton and Hedley-Whyte, 1984; Adams et al., 2007).

We report a pattern of CO staining in striate cortex of macaques raised with alternating exotropia that is consistent with the prediction that activity is reduced in the ipsilateral eye's ocular dominance columns in the peripheral representation of the visual fields. In previous studies, changes in cortical $\mathrm{CO}$ activity were induced by eye removal, eyelid suture, laser lesion, or tetrodotoxin injection (Wong-Riley, 1979; Horton, 1984; Wong-Riley and Carroll, 1984; Tychsen and Burkhalter, 1997; Horton and Hocking, 1998a). The abnormal CO activity we now describe in strabismus stems not from a reduction of 


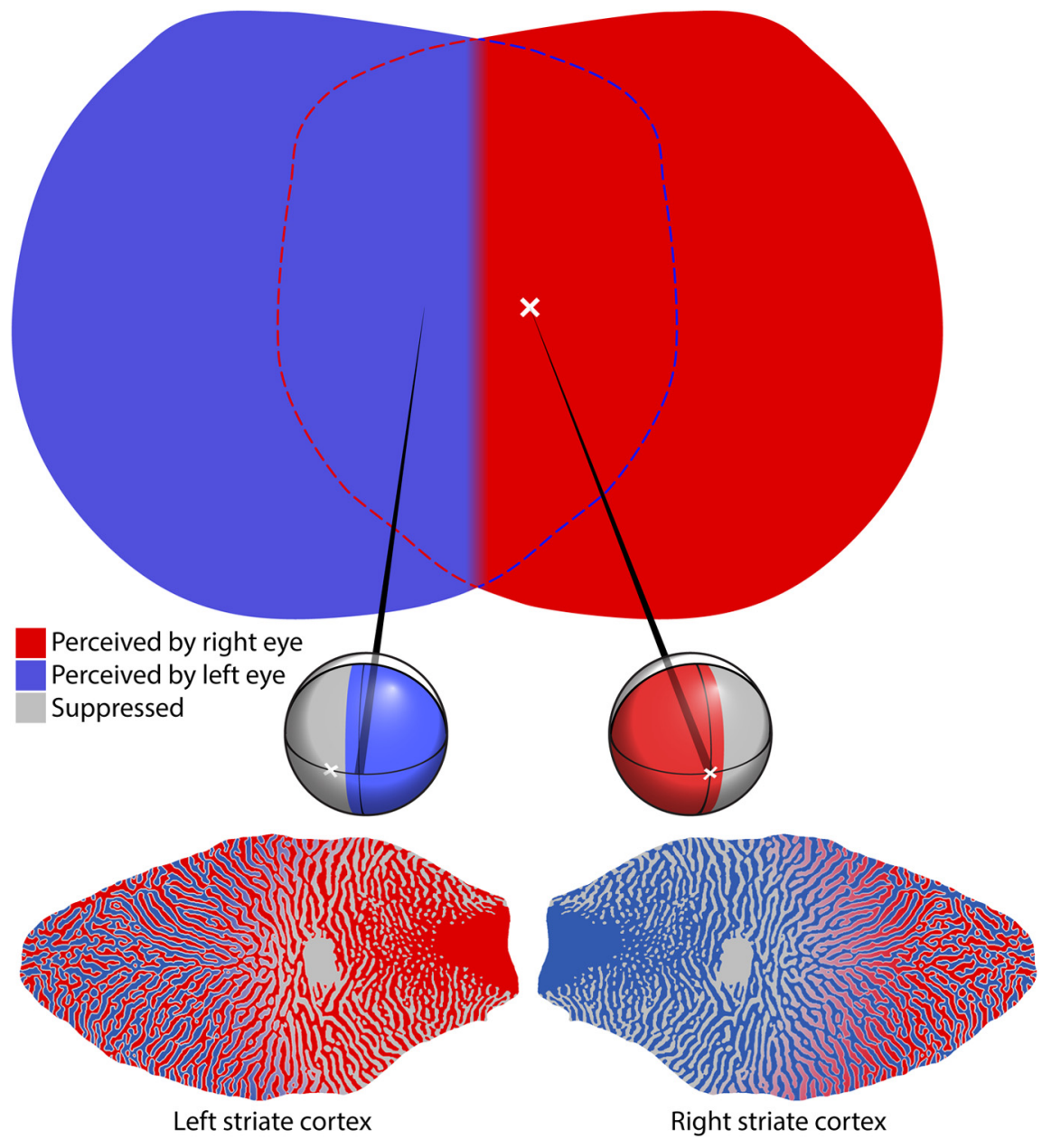

Figure 1. Schematic diagram showing perception of the visual scene by subjects with exotropia. Here, the right eye is shown looking at a central cross and the left eye is deviated by $16^{\circ}$, causing the image of the cross to land on its temporal retina. When the left eye fixates centrally, the converse occurs. Dashed lines represent the nasal extent of each eye's visual field. Blue and red shading of eyes indicates portions of each retina engaged in perception; gray shading denotes suppressed temporal retina. The smaller the exotropic deviation, the closer temporal suppression extends toward the vertical meridians in each eye. In striate cortex, dark and light $\mathrm{C} 0$ columns (depicted by blue/gray or red/gray shading) occur in the peripheral visual field representation (from $8^{\circ}$ to $64^{\circ}$ ), reflecting suppression of neuronal activity in ocular dominance columns supplied by the peripheral temporal (ipsilateral gray) retinas. In the central visual field representation (from $0^{\circ}$ to $8^{\circ}$ ), both retinas are active perceptually. Consequently, $\mathrm{CO}$ staining density is equal in the cores of the ocular dominance columns, indicated by alternating red and blue shading. It is reduced, however, in binocular border strips (thin white lines) along the edges of ocular dominance columns because fusion is absent.

retinal activity, but rather, appears to arise from inhibition of cortical activity related to visual suppression.

\section{Materials and Methods}

Experiments were conducted in four male Rhesus monkeys obtained from the California National Primate Research Center (Davis, CA). Procedures were approved by the Institutional Animal Care and Use Committees at the University of California, Davis, and the University of California, San Francisco.

In each monkey, an exotropia was induced by disinsertion of the medial rectus muscle tendon in both eyes. The procedures were performed at ages 10, 14, 26, and $32 \mathrm{~d}$. General anesthesia was provided with ketamine $\mathrm{HCl}$ ( $15 \mathrm{mg} / \mathrm{kg}$, i.m.), supplemented by local anesthesia with $1 \%$ proparacaine $\mathrm{HCl}$. After tenotomy, the muscle was released and allowed to retract into the orbit. The animals were returned to their mothers within an hour and healed rapidly from the eye muscle surgery. The day after surgery, all monkeys had a large exotropia, measuring $30-45^{\circ}$, and limited adduction in each eye.
In each animal, adduction improved gradually and the magnitude of the exotropia decreased steadily over the months following surgery. In macaques raised with exotropia caused by free tenotomy of the medial rectus muscles, the severed muscles spontaneously reattach to the globe (Economides et al., 2007). This phenomenon presumably accounts for the partial recovery of adduction and the eventual reduction in exotropia. However, the monkeys never regained fusion because their eyes were misaligned throughout the critical period for binocular vision.

Ocular alignment was measured by photographing the monkeys periodically in their cages at a distance of $\sim 1 \mathrm{~m}$, using a $100 \mathrm{~mm}$ macro lens with a ring-flash. In macaques, each millimeter of decentration of the corneal light reflex is equal to $14^{\circ}$ (Quick and Boothe, 1989). The animals' eye preference for fixation was assessed by observing their spontaneous behavior and by testing their ocular fixation while reaching for small food treats.

Two animals were killed at age 3 years by intravenous injection of pentobarbital (150 mg/ $\mathrm{kg}$ ). The unperfused, unfixed brains were removed immediately and placed into chilled 0.1 M phosphate buffer. Flatmounts of striate cortex were prepared from each hemisphere and fixed overnight in $1 \%$ paraformaldehyde and $30 \%$ sucrose. Tangential sections were cut at 60 $\mu \mathrm{m}$ on a freezing microtome and processed for CO activity.

In the remaining two animals, we injected tritiated proline to label the ocular dominance columns. After general anesthesia with ketamine $\mathrm{HCl}(20 \mathrm{mg} / \mathrm{kg}$, i.m. $)$ and topical anesthesia with $1 \%$ proparacaine $\mathrm{HCl}$, the pupils of both eyes were dilated with $1 \%$ tropicamide and $2.5 \%$ phenylephrine $\mathrm{HCl}$. Both fundi were examined with an indirect ophthalmoscope to confirm that they were normal. Two millicuries of $L$-[2,3,4,5${ }^{3} \mathrm{H}$ ] proline (PerkinElmer) in $25 \mu$ l of sterile balanced salt solution were injected into the vitreous of the right eye. The injection was made through the pars plana, $3.0 \mathrm{~mm}$ from the corneal limbus, using a 30 gauge U-100 $0.3 \mathrm{cc}$ insulin syringe. The fundus was examined immediately after the tracer injection to make sure that the retina was undamaged.

After a week to allow time for transneuronal transport, the monkey was placed under general anesthesia with ketamine $\mathrm{HCl}$. The pupil reflexes were tested for an afferent pupil defect. After pupil dilation, the fundi were examined again with an indirect ophthalmoscope. Neither monkey showed any evidence of ocular injury or inflammation from the $\left[{ }^{3} \mathrm{H}\right]$ proline tracer injection.

One monkey was killed at age 18 months, and the other animal at age 4 years. After intravenous injection of pentobarbital $(150 \mathrm{mg} / \mathrm{kg})$, transcardial perfusion was performed with normal saline followed by $1 \mathrm{~L}$ of $1 \%$ paraformaldehyde in $0.1 \mathrm{~m}$ phosphate buffer, $\mathrm{pH}$ 7.4. The entire primary visual cortex from each occipital lobe was flatmounted. The first 10 sections were cut tangentially at $40 \mu \mathrm{m}$ with a freezing microtome and processed for CO. Thereafter, alternating sections were cut either for autoradiography $(30 \mu \mathrm{m})$ or CO $(40 \mu \mathrm{m})$. Autoradiographs were processed as described previously (Horton and Hocking, 1997). Digital photographs were taken of each cortical section using a SPOT RT color CCD camera (Diagnostic Instruments) mounted on an Olympus SZH10 microscope. The columns visible in 
CO-processed sections were identified as dark or light before examining adjacent autoradiographs to determine whether they belonged to the right eye or the left eye.

\section{Results}

In two monkeys raised with alternating exotropia, the primary visual cortex in each hemisphere was processed for $\mathrm{CO}$ activity at age 3 years. In the calcarine cortex, where the peripheral visual field is represented, there were alternating pale and dark bands in layer 4C (Fig. 2). They appeared to be ocular dominance columns, but no second label was available to prove their identity. In the opercular region, where the central visual field is represented, this pattern was absent. Instead, there were pale, thin zones in layer $4 \mathrm{C}$ that resembled the border strips located along the boundaries of ocular dominance columns (Horton and Hocking, 1998a; Takahata et al., 2009). The pale strips were faint, making them difficult to appreciate, but the main point is that $\mathrm{CO}$ activity was equal in the cores of the ocular dominance columns serving each eye.

In two other monkeys, the ocular dominance columns were labeled transneuronally by injection of $\left[{ }^{3} \mathrm{H}\right]$ proline into the right eye (Wiesel et al., 1974). Figure 3 shows a monkey at age 4 years, a week before tracer injection. It had undergone eye muscle surgery at age $32 \mathrm{~d}$ to induce exotropia. The animal alternated fixation between the eyes, but had a slight preference for the right eye. The nasal decentration of the corneal light reflex in the left eye corresponded to an exotropia of $7^{\circ}$.

Figures $4 a$ and $5 a$ show flatmount sections of each primary visual cortex processed for $\mathrm{CO}$ from this monkey. These sections were chosen because large portions passed through $4 \mathrm{C}$, which is the main termination layer for projections from the lateral geniculate body. In cortex representing the central $4^{\circ}$, CO staining revealed no ocular dominance columns. Instead, there were pale thin zones in layer $4 \mathrm{C}$ (Figs. $4 b, 5 b$ ), as observed in the first two monkeys. These zones were outlined by hand (Figs. $4 d, 5 d$ ) and compared with the ocular dominance columns in adjacent autoradiographs (Figs. $4 c, 5 c$ ). The pale $\mathrm{CO}$ zones corresponded precisely to the border strips straddling the edges of ocular dominance columns (Figs. 4e, 5e).

In striate cortex representing visual field beyond the central $4^{\circ}$, there were alternating light and dark CO bands in layer 4C. In the left cortex, the pale CO columns matched the dark, unlabeled columns serving the left eye in the proline autoradiograph (Fig. $6 a, b)$. This correlation means that CO activity was reduced in ocular dominance columns supplied by the peripheral temporal retina of the ipsilateral eye. In the right cortex, the pale CO columns matched the bright, labeled proline columns of the right eye (Fig. $6 c, d$ ). Again, in this hemisphere CO activity was reduced in ocular dominance columns driven by the peripheral temporal retina of the ipsilateral eye. These findings were replicated in the other exotropic monkey that received a $\left[{ }^{3} \mathrm{H}\right]$ proline eye injection. It had an exotropia of $10^{\circ}$. At the representation of $5^{\circ}$ eccen-

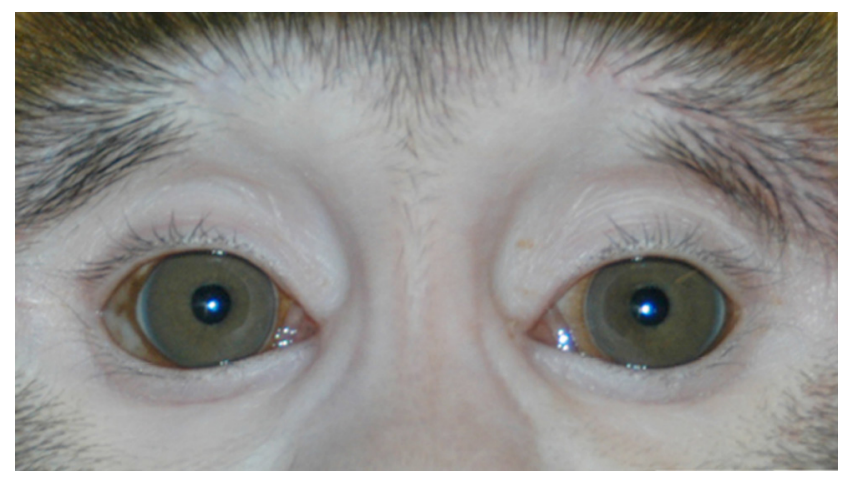

Figure 3. Assessment of exotropia. The monkey is fixating on the camera with his right eye. The left eye is deviated outward, causing nasal decentration of its corneal light reflex by $0.5 \mathrm{~mm}$ which corresponds to $7^{\circ}$. The monkey alternated fixation freely, but preferred the right eye.

tricity in each hemisphere, a transition occurred from the pale border strip pattern to the ocular dominance column pattern. Pale CO staining appeared in the columns serving the temporal, ipsilateral retina.

In each hemisphere, the pattern of alternating light and dark ocular dominance columns was interrupted by a large, oval region corresponding to the blind spot of the contralateral eye (Fig. $6 a, c$ ). In this monocular area, CO staining was uniform. The tissue in the blind spot regions qualitatively 

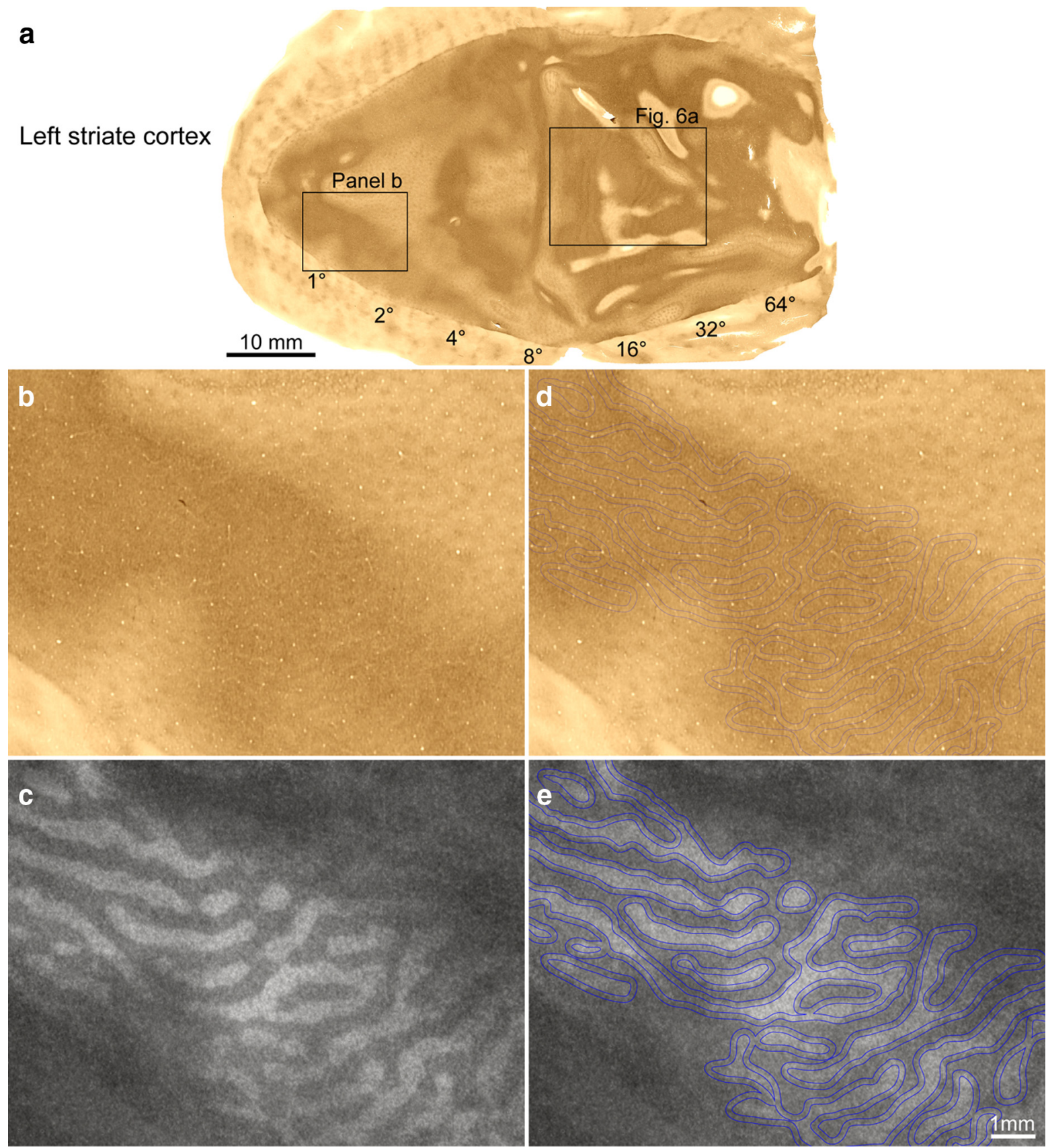

Figure 4. Patterns of $\mathrm{CO}$ activity in left striate cortex in exotropia. $\boldsymbol{a}$, Single section from a flatmount shows no ocular dominance columns in layer $4 \mathrm{C}$ from the foveal representation to an eccentricity of about $4^{\circ}$. From $4^{\circ}$ to the monocular crescent representation, there are alternating light and dark $\mathrm{CO}$ columns. $\boldsymbol{b}$, Boxed area from $1^{\circ}$ to $2^{\circ}$ in the section above. $\mathrm{C} 0$ stain reveals extremely faint, pale strips in layer $4 \boldsymbol{C}$, but no ocular dominance columns. $\boldsymbol{C}$, Adjacent $\left[{ }^{3} \mathrm{H}\right]$ proline autoradiograph labeling the ocular dominance columns in layer $4 \mathrm{C}$ in the same region. $\boldsymbol{d}$, Hand tracing of the pale $\mathrm{CO}$ strips, superimposed on the image in $\boldsymbol{b}$.e, Tracing of the pale strips in $\boldsymbol{d}$ transferred onto the autoradiograph in $\boldsymbol{c}$, showing that the pale strips straddle the borders of the ocular dominance columns.

matched the density of pale columns in the surrounding mosaic of ocular dominance columns. Striate cortex corresponding to the blind spot "representation" is supplied exclusively by temporal retina from the ipsilateral eye (Fig. $6 b, d$ ). Reduced $\mathrm{CO}$ activity in the blind spot representations was consistent with the conclusion derived from the proline autoradiographs, namely, that temporal retina in each eye serving the peripheral visual field was suppressed.

$\mathrm{CO}$ activity was abnormal in other cortical layers besides $4 \mathrm{C}$. In the central visual field representation, patches serving each eye were labeled with equal intensity in layer $2 / 3$, as were the ocular dominance columns in layer 4C. However, the rows formed by the patches were unusually distinct, owing to reduction of $\mathrm{CO}$ in the border strips situated between each row. In cortex serving the peripheral visual field, patches were arrayed in alternating light and dark rows, in register with the light and dark core zones in layer 4C (Fig. 7). The contrast between light and dark rows was subtle, compared with the strong effect of enucleation or eyelid suture (Horton, 1984), but it demonstrated that the metabolic dominance of the contralateral eye was propagated into the upper layers. Layer $4 \mathrm{~B}$ and $4 \mathrm{~A}$ also showed $\mathrm{CO}$ columns, with the darker columns serving the contralateral eye. 

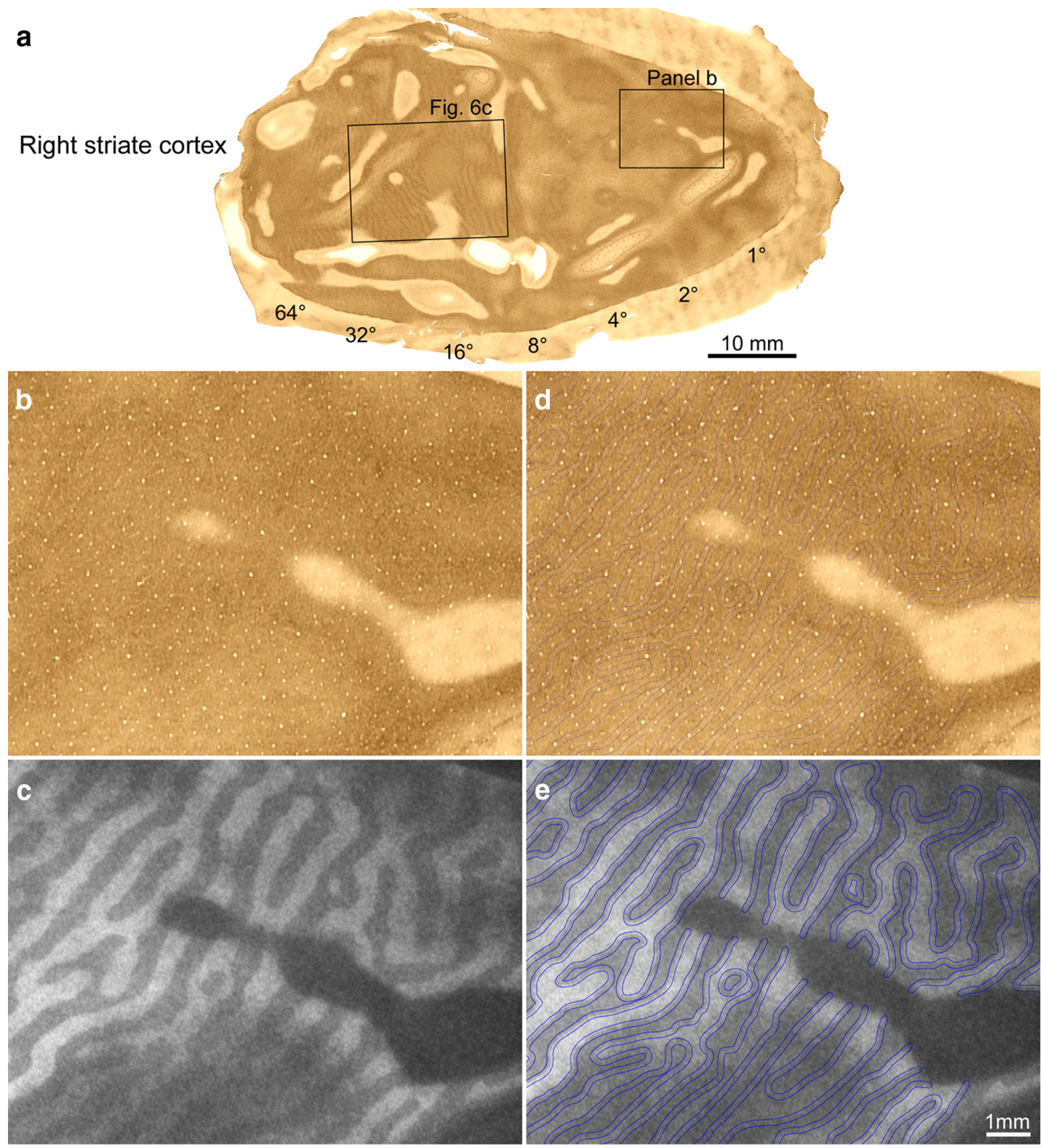

Figure 5. Patterns of $\mathrm{C} 0$ activity in right striate cortex in exotropia. $\boldsymbol{a}$, Just as in the left cortex (Fig. 4), there are no ocular dominance columns in layer $4 \mathrm{C}$ from the foveal representation to $4^{\circ}$, but from $4^{\circ}$ to the monocular crescent representation there are alternating light and dark $\mathrm{CO}$ columns. $\boldsymbol{b}$, Boxed area from central field representation of right striate cortex in $\boldsymbol{a}$, showing subtle, pale border strips in 4 C, but no pattern of ocular dominance columns. c, Adjacent autoradiograph of ocular dominance columns. $\boldsymbol{d}$, Hand tracing of pale strips, superimposed on $\boldsymbol{b}$. $\boldsymbol{e}$, Tracing in $\boldsymbol{d}$, transferred onto $c$, confirming that pale strips are located at borders of ocular dominance columns.

In area $\mathrm{V} 2$, the alternating pattern of pale-thin-pale-thick stripes was normal. This was not surprising, given that even removal of one eye does not affect the appearance of V2 CO stripes (Horton and Hocking, 1998b). Although thick stripes have been linked to stereopsis, they appear normal in animals with no stereopsis.

\section{Discussion}

The pattern of suppression that occurs in human subjects with exotropia has been tested by using a variety of manual techniques to map the visual fields (Travers, 1938; Herzau, 1980; Cooper and Record, 1986; Melek et al., 1992; Joosse et al., 1999). More recently, automated perimetry under dichoptic stimulus condi- tions has been used (Economides et al., 2012). These studies have shown that signals arising from each eye's peripheral temporal retina are suppressed in exotropia. We now provide anatomical evidence that signals emanating from the peripheral temporal retina are suppressed in the primary visual cortex. A reduction was observed in neuronal activity, assayed by $\mathrm{CO}$ staining, in ocular dominance columns serving the ipsilateral eye in the peripheral visual field representation of striate cortex in each hemisphere of monkeys raised with alternating exotropia. The reduced activity cannot be attributed to ocular injury from the $\left[{ }^{3} \mathrm{H}\right]$ proline tracer injection, because pale ocular dominance columns were also present in animals that received no eye injection. 

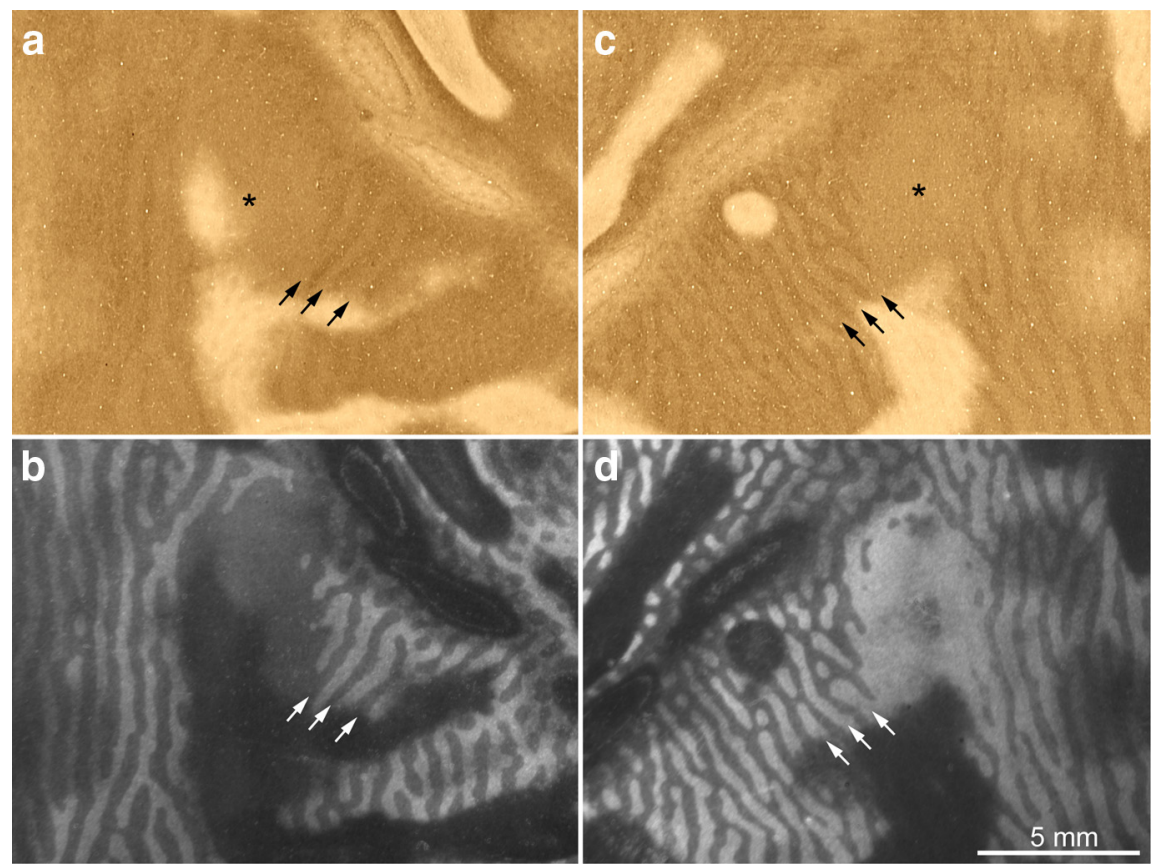

Figure 6. Reduced $C 0$ activity in ipsilateral eye's columns in cortex representing peripheral visual field. $\boldsymbol{a}$, Boxed region from the peripheral left cortex in Figure 4, showing alternating light and dark $\mathrm{C} 0$ columns surrounding the blind spot representation (asterisk), which is not complete because the lower border enters layer 5 . Three pale columns are marked with arrows. $\boldsymbol{b}$, Adjacent autoradiograph in darkfield, with dark columns representing the ocular dominance columns of the unlabeled left eye (arrows). They correspond to the pale $\mathrm{C} O$ columns above, indicating that $\mathrm{C} O$ activity is reduced in the left eye's columns. $c$, Boxed region from the peripheral right cortex in Figure 5, showing alternating light and dark $\mathrm{CO}$ columns around the blind spot. Three pale columns are marked by arrows. $\boldsymbol{d}$, Adjacent autoradiograph, showing that bright, labeled columns from the right eye match the pale columns above, indicating that $\mathrm{C} O$ activity is reduced in the right eye's columns in this hemisphere. Note solid labeling from the right eye of the left eye's blind spot "representation."
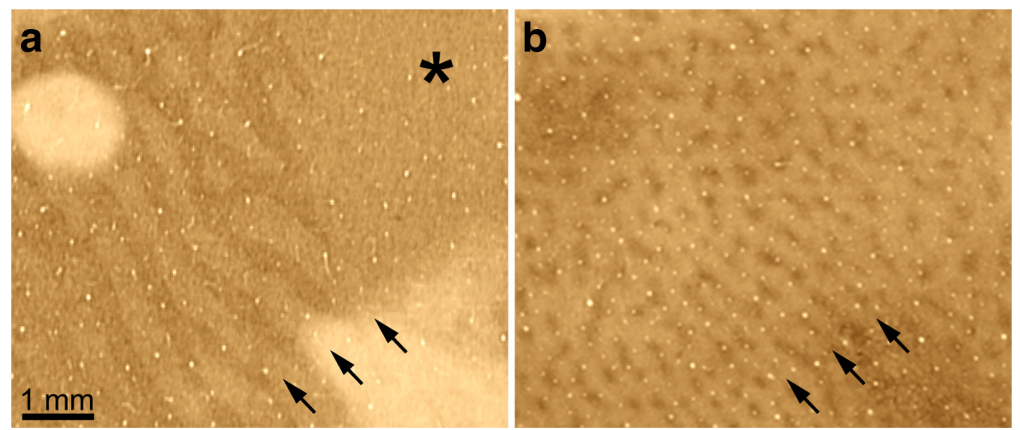

Figure 7. Suppression causes loss of $\mathrm{CO}$ activity in patches in layer 3. $\boldsymbol{a}$, $\mathrm{C}$ activity in layer $4 \mathrm{C}$ showing three pale columns serving the ipsilateral eye (arrows) in Figure $6 \mathrm{c}$ at higher magnification. The asterisk marks the blind spot area, where ocular dominance columns are absent. $\boldsymbol{b}$, Section through layer 3 from the same region, showing that patches in rows (arrows) aligned with the pale columns in layer $4 \mathrm{C}$ are slightly pale and small, compared with patches in intercalated rows serving the contralateral eye. Toward the upper right, in the blind spot area, the pattern of alternating light and dark rows of patches disappears, because only the ipsilateral eye is represented.

In the representation of the central visual fields, $\mathrm{CO}$ activity remained equal in the core zones of the ocular dominance columns serving each eye. This balanced CO activity was due to two factors. First, the monkeys alternated fixation, acquiring targets with each fovea for a substantial fraction of the time. Second, the fovea of the deviated eye probably was not suppressed. The evidence for this latter conclusion is indirect, coming from exotropic humans who alternate fixation freely and have no amblyopia. In such individuals, visual field studies have shown that the central retina of each eye is engaged simultaneously in perception (Economides et al., 2012). Although our monkeys were not tested to define regions of visual field suppression, we have shown that monkeys with exotropia from medial rectus muscle surgery alternate fixation and lack amblyopia (Economides et al., 2007).

Although ocular dominance columns were not labeled preferentially in the central visual field representation, the pattern of $\mathrm{CO}$ activity in striate cortex was not normal. There was a subtle reduction of $\mathrm{CO}$ staining along the boundaries of the ocular dominance columns in layer $4 \mathrm{C}$ in slender regions known as border strips (Horton and Hocking, 1998a; Takahata et al., 2009). In the macaque, layer $4 \mathrm{C}$ contains mostly monocular cells, but there is a small population of binocular cells along the borders of ocular dominance columns (Hubel and Wiesel, 1977; LeVay et al., 1980). In the cat, disruption of ocular alignment reduces the overall firing rate of binocular cells (Kara and Boyd, 2009). For obligatory binocular cells, the reduction is absolute (Poggio, 1995). Presumably, strabismus reduced the firing rate of binocular cells, causing a relative fall in $\mathrm{CO}$ levels within border strips. Interestingly, pale border strips are also present in newborn monkeys (Horton and Hocking, 1996a). In newborn monkeys, they disappear gradually as disparity tuning matures in binocular neurons (Endo et al., 2000).

Several previous studies have examined CO activity in striate cortex of macaques with early ocular misalignment. Tychsen and Burkhalter (1997) examined two monkeys, one with naturally occurring esotropia and another with strabismus from daily alternating ocular occlusion. In the first animal, the authors concluded that $\mathrm{CO}$ activity was reduced in the ocular dominance columns serving temporal retina. The columns were identified by intraocular injection of wheat-germ agglutinin conjugated to horseradish peroxidase (WGA-HRP). Anatomical data from one label (either CO or WGA-HRP) was compared with a drawing of the other label (Tychsen and Burkhalter, 1997, their Fig. 10). A potential problem is that WGA-HRP has the disadvantage of producing uveitis (Smecka et al., 1984; Horton and Hocking, 1996b), which can affect retinal function. It is possible that intraocular inflammation altered $\mathrm{CO}$ activity in the cortex, thereby confounding the interpretation of the metabolic patterns induced by strabismus. In the second animal, which eventually developed exotropia, the authors also concluded that $\mathrm{CO}$ activity was reduced in the ocular dominance columns serving temporal retina. However, the ocular dominance columns were not labeled with an independent tracer, so the cortical CO pattern could not be interpreted unambiguously. Fenstemaker et al. (2001) examined 
striate cortex in two monkeys raised with esotropia. In both monkeys, two patterns were observed: (1) pale border strips; and (2) alternating pale and dark ocular dominance columns. Our data are in good agreement with their results, because we also observed these two distinct CO patterns from strabismus. They were not in a position to relate the $\mathrm{CO}$ patterns to visual suppression because the identity of the columns was not established with an anatomical tracer. Together, the studies by Tychsen and Burkhalter (1997) and Fenstemaker et al. (2001) show conclusively that esotropia also produces abnormal patterns of $\mathrm{CO}$ activity in striate cortex. These intriguing patterns merit further study, comparison with ocular dominance columns, and correlation with visual suppression.

We reported abnormal CO activity in striate cortex in monkeys with ocular misalignment induced by eye muscle surgery during adulthood (Horton et al., 1999). It was suggested that regions showing pale ocular dominance columns might correspond to regions of visual field suppression in one eye. However, disruption of fusion in adults causes diplopia and is thought to create a sensory state more akin to binocular rivalry than strabismic suppression (Smith et al., 1985). For this reason, we decided to examine CO patterns in macaques with exotropia since infancy. The CO staining abnormalities are similar in monkeys raised with strabismus and those with adult-onset ocular misalignment. Because visual suppression is nearly universal in subjects with strabismus since infancy (von Noorden and Campos, 2002), it is reasonable to infer that the loss of CO activity in the ipsilateral eye's columns in peripheral cortex is a functional correlate of suppression. This inference is supported by the correspondence between the $\mathrm{CO}$ staining pattern in exotropic monkeys and the visual field suppression data from exotropic humans (Fig. 1).

In Figure 6, $a$ and $c$, the CO staining in the blind spot representation is pale in each hemisphere, relative to the dark CO activity in the surrounding ocular dominance columns that serve the contralateral eye. The blind spot representation appears pale, because it is supplied only by ipsilateral temporal retina, which is suppressed in exotropia. Why should temporal retina be suppressed at a cortical locus that corresponds anatomically to the optic disc in the other eye? The likely reason is that in exotropia, the region in the temporal retina that would normally fill in the other eye's blind spot overlaps instead with a point near the other eye's center of gaze (Fig. 1). Therefore, suppression of this region of temporal retina is necessary to avoid diplopia.

It has been unclear what neural mechanism enables children with strabismus to avoid diplopia, or where visual suppression takes place in the brain. These data provide anatomical evidence that suppression is mediated at the level of the primary visual cortex. This point in the visual pathway is logical, because it is the first place in the cerebral cortex where ocular inputs are brought together and the last place where they remain segregated. However, it remains unknown whether suppression originates in the lateral geniculate nucleus or striate cortex, or is governed by feedback projections from higher visual cortical areas that must reconcile conflicting images (Logothetis et al., 1996).

In striate cortex, intrinsic horizontal connections extend for only a few millimeters (Rockland and Lund, 1983; Fitzpatrick et al., 1985; Yoshioka et al., 1996; Bosking et al., 1997). This would not be sufficient, for example, to allow neurons serving the fovea in one eye's ocular dominance columns to inhibit directly neurons serving the peripheral temporal retina in the other eye's ocular dominance columns. Moreover, strabismus leads to a selective loss of projections between cells in opposite ocular domi- nance columns (Löwel and Singer, 1992; Tychsen et al., 2004; Schmidt and Löwel, 2008), reducing the substrate for such inhibitory interactions. For these reasons, feedback from cells in higher visual cortical areas, which have much larger receptive fields, is more likely to control interocular suppression.

\section{References}

Adams DL, Sincich LC, Horton JC (2007) Complete pattern of ocular dominance columns in human primary visual cortex. J Neurosci 27:1039110403. CrossRef Medline

Bosking WH, Zhang Y, Schofield B, Fitzpatrick D (1997) Orientation selectivity and the arrangement of horizontal connections in tree shrew striate cortex. J Neurosci 17:2112-2127. Medline

Cooper J, Record CD (1986) Suppression and retinal correspondence in intermittent exotropia. Br J Ophthalmol 70:673-676. CrossRef Medline

Cotter SA, Tarczy-Hornoch K, Song E, Lin J, Borchert M, Azen SP, Varma R (2009) Fixation preference and visual acuity testing in a populationbased cohort of preschool children with amblyopia risk factors. Ophthalmology 116:145-153. CrossRef Medline

Daniel PM, Whitteridge D (1961) The representation of the visual field on the cerebral cortex in monkeys. J Physiol 159:203-221. Medline

Deyoe EA, Trusk TC, Wong-Riley MT (1995) Activity correlates of cytochrome oxidase-defined compartments in granular and supragranular layers of primary visual cortex of the macaque monkey. Vis Neurosci 12:629-639. CrossRef Medline

Economides JR, Adams DL, Jocson CM, Horton JC (2007) Ocular motor behavior in macaques with surgical exotropia. J Neurophysiol 98:3411-3422. CrossRef Medline

Economides JR, Adams DL, Horton JC (2012) Perception via the deviated eye in strabismus. J Neurosci 32:10286-10295. CrossRef Medline

Endo M, Kaas JH, Jain N, Smith EL 3rd, Chino Y (2000) Binocular crossorientation suppression in the primary visual cortex (V1) of infant rhesus monkeys. Invest Ophthalmol Vis Sci 41:4022-4031. Medline

Fenstemaker SB, Kiorpes L, Movshon JA (2001) Effects of experimental strabismus on the architecture of macaque monkey striate cortex. J Comp Neurol 438:300-317. CrossRef Medline

Fitzpatrick D, Lund JS, Blasdel GG (1985) Intrinsic connections of macaque striate cortex: afferent and efferent connections of lamina 4C. J Neurosci 5:3329-3349. Medline

Herzau V (1980) Untersuchungen über das binokulare gesichtsfeld schielender. Doc Ophthalmol 49:221-284. CrossRef Medline

Horton JC (1984) Cytochrome oxidase patches: a new cytoarchitectonic feature of monkey visual cortex. Philos Trans R Soc Lond B Biol Sci 304:199-253. CrossRef Medline

Horton JC, Hedley-Whyte ET (1984) Mapping of cytochrome oxidase patches and ocular dominance columns in human visual cortex. Philos Trans R Soc Lond B Biol Sci 304:255-272. CrossRef Medline

Horton JC, Hocking DR (1996a) An adult-like pattern of ocular dominance columns in striate cortex of newborn monkeys prior to visual experience. J Neurosci 16:1791-1807. Medline

Horton JC, Hocking DR (1996b) Anatomical demonstration of ocular dominance columns in striate cortex of the squirrel monkey. J Neurosci 16:5510-5522. Medline

Horton JC, Hocking DR (1997) Timing of the critical period for plasticity of ocular dominance columns in macaque striate cortex. J Neurosci 17: 3684-3709. Medline

Horton JC, Hocking DR (1998a) Monocular core zones and binocular border strips in primate striate cortex revealed by the contrasting effects of enucleation, eyelid suture, and retinal laser lesions on cytochrome oxidase activity. J Neurosci 18:5433-5455. Medline

Horton JC, Hocking DR (1998b) Effect of early monocular enucleation upon ocular dominance columns and cytochrome oxidase activity in monkey and human visual cortex. Vis Neurosci 15:289-303. Medline

Horton JC, Hocking DR, Adams DL (1999) Metabolic mapping of suppression scotomas in striate cortex of macaques with experimental strabismus. J Neurosci 19:7111-7129. Medline

Hubel DH, Wiesel TN (1977) The Ferrier lecture: functional architecture of macaque monkey visual cortex. Proc R Soc Lond B Biol Sci 198:1-59. CrossRef Medline

Joose MV, Simonsz HJ, de Jong PT (2000) The visual field in strabismus: a historical review of studies on amblyopia and suppression. Strabismus 8:135-149. CrossRef Medline 
Joosse MV, Simonsz HJ, van Minderhout EM, Mulder PG, de Jong PT (1999) Quantitative visual fields under binocular viewing conditions in primary and consecutive divergent strabismus. Graefes Arch Clin Exp Ophthalmol 237:535-545.

Kara P, Boyd JD (2009) A micro-architecture for binocular disparity and ocular dominance in visual cortex. Nature 458:627-631. CrossRef Medline

LeVay S, Wiesel TN, Hubel DH (1980) The development of ocular dominance columns in normal and visually deprived monkeys. J Comp Neurol 191:1-51. CrossRef Medline

LeVay S, Connolly M, Houde J, Van Essen DC (1985) The complete pattern of ocular dominance stripes in the striate cortex and visual field of the macaque monkey. J Neurosci 5:486-501. Medline

Logothetis NK, Leopold DA, Sheinberg DL (1996) What is rivalling during binocular rivalry? Nature 380:621-624. CrossRef Medline

Löwel S, Singer W (1992) Selection of intrinsic horizontal connections in the visual cortex by correlated neuronal activity. Science 255:209-212. CrossRef Medline

Melek N, Shokida F, Dominguez D, Zabalo S (1992) Intermittent exotropia: a study of suppression in the binocular visual field in 21 cases. Binocular Vis Quart 7:25-30.

Poggio GE (1995) Mechanisms of stereopsis in monkey visual cortex. Cereb Cortex 5:193-204. CrossRef Medline

Quick MW, Boothe RG (1989) Measurement of binocular alignment in normal monkeys and in monkeys with strabismus. Invest Ophthalmol Vis Sci 30:1159-1168. Medline

Rockland KS, Lund JS (1983) Intrinsic laminar lattice connections in primate visual cortex. J Comp Neurol 216:303-318. CrossRef Medline

Schmidt KF, Löwel S (2008) Strabismus modifies intrinsic and inter-areal connections in cat area 18. Neuroscience 152:128-137. CrossRef Medline

Smecka Z, Stankus P, Lichnovský V (1984) Experimental uveitis in rabbits induced with BSA and horseradish peroxidase. Acta Univ Palacki Olomuc Fac Med 106:139-144. Medline

Smith EL 3rd, Levi DM, Manny RE, Harwerth RS, White JM (1985) The relationship between binocular rivalry and strabismic suppression. Invest Ophthalmol Vis Sci 26:80-87. Medline

Takahata T, Higo N, Kaas JH, Yamamori T (2009) Expression of immediate-early genes reveals functional compartments within ocular dominance columns after brief monocular inactivation. Proc Natl Acad Sci U S A 106:12151-12155. CrossRef Medline

Travers TA (1938) Suppression of Vision in Squint and Its Association with Retinal Correspondence and Amblyopia. Br J Ophthalmol 22:577-604. CrossRef Medline

Tychsen L, Burkhalter A (1997) Nasotemporal asymmetries in V1: ocular dominance columns of infant, adult, and strabismic macaque monkeys. J Comp Neurol 388:32-46. CrossRef Medline

Tychsen L, Wong AM, Burkhalter A (2004) Paucity of horizontal connections for binocular vision in V1 of naturally strabismic macaques: cytochrome oxidase compartment specificity. J Comp Neurol 474:261-275. CrossRef Medline

Van Essen DC, Newsome WT, Maunsell JH (1984) The visual field representation in striate cortex of the macaque monkey: asymmetries, anisotropies, and individual variability. Vision Res 24:429-448. CrossRef Medline

von Noorden GK, Campos EC (2002) Binocular vision and ocular motility: theory and management of strabismus, Ed 6. St. Louis, MO: Mosby.

Wiesel TN, Hubel DH, Lam DM (1974) Autoradiographic demonstration of ocular-dominance columns in the monkey striate cortex by means of transneuronal transport. Brain Res 79:273-279. CrossRef Medline

Wong-Riley M, Carroll EW (1984) Effect of impulse blockage on cytochrome oxidase activity in monkey visual system. Nature 307:262-264. CrossRef Medline

Wong-Riley M (1979) Changes in the visual system of monocularly sutured or enucleated cats demonstrable with cytochrome oxidase histochemistry. Brain Res 171:11-28. CrossRef Medline

Yoshioka T, Blasdel GG, Levitt JB, Lund JS (1996) Relation between patterns of intrinsic lateral connectivity, ocular dominance, and cytochrome oxidase-reactive regions in macaque monkey striate cortex. Cereb Cortex 6:297-310. CrossRef Medline 